\title{
The Beginnings of Expertise for Ballads
}

\author{
DAVID C. RUBIN \\ WANDA T. WALLACE \\ BARBARA C. HOUSTON \\ Duke University
}

\begin{abstract}
To study the beginning stages of expertise, 14 students, who were inexperienced with ballads, heard and recalled a series of 5 ballads over the course of 5 weeks. Compared with their first recall of the first ballad, their first recall of the fitth ballad had one and a half times as many words, two times as many rhyming words, and three times as much line structure evident in the written recall protocols. Compared with novices, the 14 beginning experts more often filled in blank spaces in novel ballads with words of the correct number of syllables and more often chose the original stanza of a novel ballad that was paired with a changed version of the stanza. The beginning experts were also able to compose, in 20 $\mathrm{min}$, ballads about two thirds as long as the 10-stanza ballads they learned. Thirty characteristics were identified in the set of the five learned ballads. The ballads composed by the beginning experts used over half of these. The beginning experts also explicitly stated about one quarter of these 30 characteristics, but there was no statistical relationship between the characteristics used and the characteristics stated. Memory expertise is viewed as a pervasive aspect of cognition in which people make use of a variety of regularities in the material to be learned.
\end{abstract}

In 1949, Harlow, reviewing this work on repeated choice tasks with monkeys and children, noted that

The variety of learning situations that play an important role in determining our basic personality characteristics and in changing some of us into thinking animals are repeated many times in similar form. The behavior of the human being is not to be understood in terms of the results of single learning situations but rather in terms of changes which are affected through multiple, though comparable, learning problems.... This learning to learn transforins the organism from a creature that adapts to a changing environment by trial and error to one that adapts by seeming hypothesis and insight. (p. .51)

All reported ef fects are significant at the .05 level unless otherwise noted.

We wish to thank John Bransford, Arnold Glass, Keith Holyoak and Ian Hunter for their comments, the two professional singers, Margaret and Wayne Martin, and above all, the students for their help. Support was provided by NSF grants number BNS-8410124 and number BNS-9010174.

Correspondence and requests for reprints should be sent to David C. Rubin, Department of Experimental Psychology, Duke University, Durham, NC 27708-0086. 
Research on human memory has concentrated on "the results of single learning situations," but not exclusively. The problem of memory expertise has had a small but long and continuous history in mainstream memory research. Ericsson (1985), for example, reviewed studies of highly skilled memory experts by Binet from 1884, Mueller from 1917, Bousfield and Barry from 1933, Luria from 1968, Hunt and Love from 1972, Chase and Simon from 1973, Hunter from 1977, and Ericsson and Polson from 1984. Other studies have been added to the literature since the Ericsson article was published (Holding, 1985; Intons-Peterson \& Smyth, 1987; Noice, 1991, 1992; Thompson et al., 1991). Similarly, Neisser (1982) reprinted several articles on memory experts. In the last two decades the detailed investigation into possible mechanisms that allow expertise has expanded, including studies in which single subjects were trained to high levels of expertise (Chase \& Ericsson, 1981; Ericsson \& Harris, 1990; Staszewski, 1989). The basic assumptions and findings of this research effort that are relevant to this study follow.

Memory expertise is not a rare or aberrant phenomenon to be added to a museum of memory marvels, but a common, normal result of routine cognitive processes (e.g., James, 1890; Neisser, 1982). Everyone is a memory expert in many tasks and domains. We are in awe of memory expertise only when it occurs for unusual tasks and domains, ignoring the more common occurrences.

Memory expertise is limited to specific tasks, domains, and genres (e.g., Glaser \& Chi, 1988). It is a specific set of skills, not a general ability to remember all materials or perform all memory tasks. For instance, Harlow's (1949) monkeys trained to be experts on novel choice tasks needed additional training to become experts on reversal-learning choice tasks. Although people vary in their general interests and abilities in ways that contribute to expertise (Ackerman, 1987; Hunter, 1990; Luria, 1968), the largest component of expertise is due to specific skills, not general faculties (see Singley \& Anderson, 1989 , for a history of the early psychological and philosophical debate on this general issue). A large digit span does not imply a large consonant span (Chase \& Ericsson, 1981), and the ability to recall the location of pieces from a chess game (Chase \& Simon, 1973) or cards from a bridge hand (Engle \& Bukstel, 1978) does not imply a large digit span or even a good memory for randomly arranged chess pieces or playing cards.

Memory expertise in any domain requires a large body of knowledge, even though the knowledge need not always be explicitly statable or usable in tasks different from those usually performed (Smith, 1990). Moreover, the knowledge needs to be organized in a way that allows rapid use for the expert task. In particular, expertise involves the ability to grasp organized, domain-specific stimuli quickly. A chess expert can remember a chess board that has been exposed for only seconds (Chase \& Simon, 1973). For the work that follows here, the speed needs to be sufficient to allow the use of structures in complex auditory stimuli presented in real time. 
Using their knowledge, memory experts organize the stimuli presented to them to a greater extent and in different ways than novices. This is often summarized as experts find "meaningful" patterns whereas novices do not. But as will be shown here, meaningful must be taken to mean task-(Morris, Bransford, \& Franks, 1977) and stimulus-appropriate (Rubin, 1985) rather than deep or semantic.

Memory expertise requires practice, but formal teaching is not needed. Motivated subjects can acquire the skills through trial and error attempts, much like Harlow's (1949) monkeys. This is important for the generality of the studies presented here, because in many domains, including most oral traditions, there is no formal training beyond such repetition (Rubin, 1988b).

Like Harlow (1949), we wanted to see how learning a set of related, but different, stimuli affected the learning of new stimuli. Oral tradition ballads were chosen as the domain to investigate for at least three reasons. First, novices can be selected based on criteria other than the desire to become expert ballad singers. People are often drawn to their domain of expertise by individual differences in ability or motivation (Hunter, 1990). Crosssectional studies that compare existing experts to a sample of randomly assigned novices confound differences in ability and motivation between the two groups that existed prior to the development of expertise with what was learned while becoming an expert. In contrast, a longitudinal study in which subjects are selected without regard for ability or motivation can assess learning effects unconfounded by these factors. Because progress can be shown in a few trials, it is possible to use a group of subjects instead of just one individual as is common in most longitudinal studies of the development of expertise (Chase \& Ericsson, 1981; Ericsson \& Harris, 1990; Staszewski, 1989; for an exception, see Schoenfeld \& Herrmann, 1982).

Second, ballads have been handed down for centuries with remarkable stability, and something is known about the causes of this stability (Wallace, 1991, 1992; Wallace \& Rubin, 1988a, 1988b, 1991). In particular, ballads are a highly structured stimulus domain with many different characteristics that play individual and interacting roles in making ballads easy for those who are experts in the genre to learn and remember (Wallace \& Rubin, 1991). The characteristics are valuable for encoding, retrieval, and informed guessing. The characteristics chunk and link words to lines and stanzas as well as linking stanzas to ballads as a whole. For instance, the rhythm provides a clue about how many syllables exist in a line, thereby letting the singer know when everything has been retrieved or when further search is necessary. End rhyme links the lines within a stanza. The music provides a marker for the beginning of the next stanza so that if one stanza is omitted or forgotten, the singer can skip to the beginning of the next stanza (Wallace, 1991, 1992). The story line provides an overall organization for the ballad. That is, there are many characteristics that have been specified and studied and that can operate simultaneously and in combination to produce a recall. In contrast, 
most psychology experiments, including those where subjects learn more than one text (e.g., Thorndyke, 1977) concentrate on one form of organization, usually meaning.

Third, included among the characteristics of ballads are many that are of surface linguistic organization as opposed to meaning. It is common in the expertise literature to find that with increasing expertise there is less reliance on surface forms (Chi, Feltovich, \& Glaser, 1981; Dee-Lucas \& Larkin, 1988; Novick, 1988; Schoenfeld \& Herrmann, 1982; Smith, 1990). In ballads, surface organization is important for memory, allowing a view based on surface versus deep or meaningful organization to be contrasted with one based on the regularities available (Rubin, Stolzfus, \& Wall, 1991) or with transfer-appropriate processing (Morris et al., 1977). In particular, rhyme and rhythm are surface characteristics that can consistently aid chunking, cuing, and informed guessing in remembering ballads. Using these surface characteristics can be as task-appropriate for ballads as using an abstract theme. The literature on verbal memory distinguishes between linguistic surface and deep structures, whereas the literature on problem solving (Holyoak \& Koh, 1987) distinguishes between surface (i.e., not causally relevant to a goal) and structural (i.e., causally relevant to a goal) similarity. The point being made here is that although rhyme and rhythm are surface in the linguistic sense of the word, they are not in the problem-solving sense.

\section{METHOD}

\section{Subjects}

Fourteen students took part in the expertise experiment. Thirteen students enrolled in introductory psychology courses served as control subjects for the cloze task to match the number of novice experts who finished that task. An additional 100 students served as control subjects for the choice task.

\section{General Procedure}

The data collected for this project were part of a laboratory course on expertise. During the 1st week of the course, a practice story was learned and a questionnaire on exposure to a sample of 29 ballads was completed to insure that none of the subjects knew any of the ballads to be learned or had expertise in ballad singing in general. The practice story was used to familiarize the subjects with the procedure and apparatus was "The son who tried to outwit his father" (Bartlett, 1932).

During each of the next 5 weeks of the course, one ballad was learned. For the next 2 weeks, an assortment of tasks assessed the subjects' knowledge of ballad structures. The subjects then analyzed, individually and as a group, the data they had produced. 


\section{Learning Sessions}

Materials. Five traditional ballads were chosen from the Brown collection (White, 1952). The ballads followed by their number in the Brown, and in the Child (1882-1898) collections when applicable, are: Lord Thomas and Fair Annet (Brown 19M, Child 73), The Girl I Left Behind (Brown 145B), Earl Brand, now more commonly known as Sweet William and Fair Annet (Brown 3B, Child 7), The Lexington Murder (Brown 65A), and James Harris, now more commonly known as The House Carpenter (Brown 40A, Child 243). The ballads were chosen from the popular ballad set of Wallace and Rubin (1991) because they all had a similar story line. To provide ballads of approximately equal length, the 10 stanzas that best told the story were selected from each ballad. A few words of the original ballads were altered to change archaic or regional language. The ballads averaged 266 words each.

A master tape was made in a university recording studio by two professional singers who were familiar with the ballad tradition. The singers alternated reading the practice story so that subjects could become familiar with both voices. One singer performed the first and last ballads; the other performed the middle three ballads. From this master tape an experimental tape was made with the identical version of the sung ballad repeated five times with a 1-min rest interval between repetitions. Transcripts of the first and last ballads, as modified for this study, are listed in the Appendix.

Individual answer sheets were prepared for each learning session containing a subject number, date, and lined pages on which to record the recalls of that day's ballad and comments about the learning process.

Procedure. During the learning session for the practice story and for the five ballads, each subject heard a tape of the story or ballad once through headphones, recalled as much as possible in writing, heard the story or ballad repeated four more times, attempted a second recall, and then wrote any comments about "thoughts during the learning and recall." The procedure was described to the subjects who were instructed to recall the story or ballad as accurately as they could within a 15 -min period, leaving blanks where they knew they had left out information. Subjects were asked to provide verbatim recall where possible. The singing of each ballad was between 3 and $4 \mathrm{~min}$. The individual subject's recalls lasted between 3 and $10 \mathrm{~min}$ for the first recall of the ballad in each session and between 8 and $15 \mathrm{~min}$ for the second recall of the ballad. Thus, subjects were exposed to each ballad for about $18 \mathrm{~min}$ of singing, $3 \mathrm{~min}$ of rehearsal, and $18 \mathrm{~min}$ of recall. During the week following the learning sessions, a delayed recall was made of the ballads learned in the first and last sessions.

Half the subjects heard the ballads in the order listed in the Materials section, and the other half heard them in the reverse order. Thus, the ballad 
learned in the first session by each half of the subjects was learned in the fifth (i.e., last) session by the other half of the subjects. Although the ballads learned in the intermediate sessions are as similar in structure and difficulty as we could find, direct quantitative comparisons among the intermediate and the first and last sessions are not possible.

\section{Composition of a New Ballad}

During the week following the last recalls, subjects were given two sheets of lined paper with the following typed instructions: "One way to test if you have learned the rules and structure of ballads is to have you generate a new one. Therefore, I would like you to try to make up a ballad that a critic would find difficult to pick out as yours if it were mixed among the set of five ballads you learned. Do not worry about overall length...." Twenty min were allowed for this task. Similar tasks have proved successful with traditional ballad singers (Wallace, 1991; Wallace \& Rubin, 1988a) and with tests of undergraduates' knowledge of other domains (Rubin \& Kontis, 1983; Rubin et al., 1991). This task is a way of assessing subjects' knowledge that excludes rote recall. To satisfy the request successfully, the subjects either had to modify one learned ballad using their knowledge of other ballads or combine aspects of more than one ballad in a way that produced a coherent whole, or apply generalized rules they had abstracted or in some other way go beyond the recall of one ballad.

\section{Listing Rules}

After a short break immediately following the composition task, subjects were given two additional sheets of lined paper with typed instructions: "Please record the rules, generalizations, or properties of the five ballads you learned... . Include comments on both the content and the structure." Twenty min were allowed for this task. This task provides a comparison between the subjects' conscious, explicit, "knowledge that" the learning ballads have certain properties and their "knowledge how" to compose a ballad, which was tested in the previous task.

\section{The Cloze Procedure}

The week following the generation and rule-listing tasks, the experimental subjects performed a cloze task and immediately after it a forced-choice task. Variants of three ballads, The House Carpenter (Brown 40A, Child 243), which was part of the learning set, Barbara Allen (Brown 27A, Child 84), and The Wreck of the Old '97 (Brown, 217A) (Wallace \& Rubin, 1988b) were presented in stanza form, each on a separate sheet of paper. Starting with the third word, every fifth word was replaced with a blank of uniform length. The House Carpenter and Barbara Allen were each shortened to 10 stanzas. Seven of the 10 stanzas of The House Carpenter overlapped with the 10 used in the learning sessions. 
One experimental subject was not present for this task, leaving 13 beginning experts. Data from 13 control subjects from introductory psychology courses were obtained. The two groups were matched on their preexperimental exposure to ballads as measured by a questionnaire. The cloze procedure was included to test whether the subjects' knowledge of ballads would let them choose words that would fit the constraints, thereby increasing their probability of guessing word choices.

\section{The Choice Procedure}

Ten ballads were selected from the same popular ballad set from which the learning ballads were drawn and each was reduced to 10 stanzas. Four of these ballads were among the five ballads of the learning set, two were of a similar theme but not among those in the learning set, and four were of different themes than the learning set. For each stanza in each ballad, 10 alternative versions were formed. Each alternative was intended to change only one feature of the ballad, but because we could not change just one factor without affecting others, and because only 14 expert subjects were available, we collapsed over the different changes in the analyses that follow. For each of the ten ballads, each change occurred once in each position from the first to the last stanza. The 10 changes were: (1) breaking the end rhyme scheme by substituting a synonym or inverting word order; (2) breaking the rhythm by substituting a synonym, or inverting word order; (3) breaking an alliteration by substituting a synonym; (4) negating the meaning of a line by introducing a no, not, or antonym; (5) selecting the same stanza from a different variant of the ballad that did not fit the style or poetics of the variant used; (6) introducing a vocabulary word that would not appear in a traditional ballad; (7) changing the four-line stanza structure to three or five lines by dropping or repeating a line; (8) replacing a line with an equal number of syllables of repeated tra la la's; (9) running the meaning of one line onto the next (enjambement) by breaking a line at a different place; and (10) reordering the lines.

Subjects were presented with 10 sheets of paper each containing a complete ballad in a column on the left and the same ballad in a column on the right. Half the original stanzas were on each side. The subject's task was to choose the "original" version of each stanza. In all, 100 counterbalanced orders were produced and 100 control subjects drawn from introductory psychology courses completed them. From these 100 orders, 14 were selected randomly for the expert subjects.

In the transmission of ballads in oral traditions, more than one variant of a ballad is often heard, and a singer must form a variant based on these different sources. If a variant is heard that, in part, does not fit the constraints of the genre, then the singer should know not to select or retain that part of the ballad. The choice task was intended to see if the subjects' ability to 

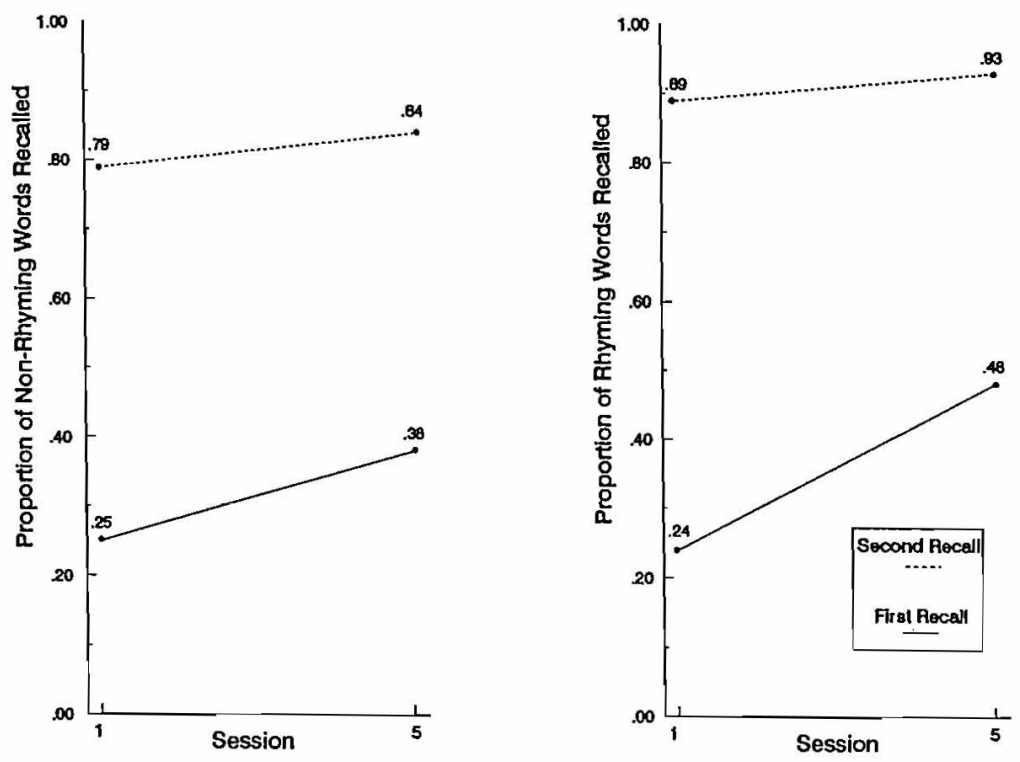

Figure 1. The left panel shows the proportion of words recalled verbatim, which within the accuracy of the figure, is equal to the proportion of nonrhyming words recolled verbatim. The right panel gives the same information for the rhyming words at the end of lines 2 and 4 of the ballads.

choose the better of two choices was more accurate than subjects who had not learned the five ballads.

\section{Results}

Learning Sessions: Recall. The recalls were scored in two ways, verbatim and gist. For the verbatim scoring, the number of words in a line of recall that exactly matched words in the same line of the stimulus ballad were counted. Misspellings were allowed, and continuous sections of the recall protocols were assigned to lines that provided the best fit to the original 'ballad.

A repeated-measures ANOVA compared the proportion of correct verbatim recall with learning session (first vs. last) and recall trial within learning session (first vs. second) as within factors. More words were recalled in the last learning session than in the first, $F(1,13)=10.06$, and more were recalled in the second recall trial of each learning session than in the first, $F(1,13)=279.74$. There was no interaction, $F(1,13)=2.68, p=.12$. Thus, as shown in the left panel of Figure 1, subjects could benefit from their learning experience and recall more after being presented with five ballads than after one. 
Gist scoring was done by two paid judges, naive to the purposes of the experiment, who rated each line in the original ballad for the extent that it was recalled on a 5-point scale ranging from none of the meaning (1) through about half of the meaning (3) to essentially all of the meaning (5). To produce a scale with a minimum of 0.00 and a maximum of $1.00,1.00$ was subtracted from each rating, the ratings were summed over the 40 lines of each recall, and the sum was divided by the maximum possible sum of 160 . The correlation of the two judges' scorings calculated over all 56 recall protocols (1 recall from each of the four conditions shown in the left panel of Figure 1 from each of the 14 subjects) was .99 . The scores of the two judges were therefore averaged.

A repeated-measures ANOVA compared the proportion of gist recall, with learning session (first vs. last) and recall trial within learning session (fist vs. second) as within factors. The gist scoring gave results similar to the verbatim scoring. More was recalled in the last learning session than the first, $F(1,13)=11.79$, and more was recalled in the second recall trial of each learning session than in the first, $F(1,13)=150.18$. The means for the first recall trial during the first and the last learning session were .30 and .50 . The means for the second recall trial during the first and the last learning sessions were .89 and .95 . There was a nearly significant interaction, $F(1,13)=3.76$, $p=.07$, which is caused by a ceiling effect, with second recall trial on both learning sessions being near perfect in terms of gist.

Learning Sessions: Constraints. Measures were made of the subjects' use of the most prominent aspects of ballad organization: rhyme and line structure. Rhyme, especially end rhyme, is the most noticeable of the soundpattern repetitions used in English (e.g., Hyman \& Rubin, 1990; Wallace \& Rubin, 1991). Line structure provides the basis for the regular iambic rhythm of the ballads. These measures were selected not only because of their importance in ballads, but also because they occurred frequently enough to allow for stable observation, could be judged reliably, and could be the basis of indices that were independent of the amount-recalled measures.

The most common rhyme scheme of the ballads (Wallace \& Rubin, 1991), and the one used in the sample of ballads used here, is ABCB. Therefore, the last words of lines 2 and 4 of each stanza that had a rhyme were examined, and the proportion of these words that were recalled either verbatim or with a change that preserved the rhyme was recorded for each recall protocol. The proportion of nonrhyming words recalled provided a comparison measure. Because $96 \%$ of the words in the ballads were nonrhyming words, this measure is nearly equivalent to the verbatim recall measure with the group means for both measures within $1 \%$ of each other. Thus, the left panel of Figure 1 serves as both an indication of the recall of all words and of all nonrhyming words. 
A repeated-measures ANOVA was conducted for verbatim recall with learning session (first vs. last), recall trial within learning session (first vs. second), and rhyme level (rhyming and nonrhyming words) as within-subject factors. There were main effects of learning session, $F(1,13)=13.81$, recall trial, $F(1,13)=234.62$, and rhyme level, $F(1,13)=17.34$. The two-way interaction of learning session and recall trial is significant, $F(1,13)=8.73$. Finally, the three-way interaction of rhyme level, learning session, and recall trial within learning session is significant, $F(1,13)=5.09$.

As shown in the right panel of Figure 1, the proportion of rhyming words recalled on the first recall trial of learning Sessions 1 and 5 is .24 and .48, respectively. This compares with values of .25 and .38 for the nonrhyming words shown in the left panel. Thus, subjects are equally likely to recall a rhyming as a nonrhyming word after hearing the first ballad once, $F(1,13)=$ $0.66, p=.43$, but are more likely to recall a rhyming word after hearing their fifth ballad once, $F(1,13)=5.87$. For the second recall trial of the first and last learning session rhyming words were recalled in .89 and .93 of the cases compared with .78 and .84 for the nonrhyming words. Thus, there is a general improvement in the second recall of rhyming and nonrhyming words across learning sessions with subjects failing to recall about twice as many nonrhyming as rhyming words. The large increase in the recall of rhyming words on the first recall trial of the last learning session leads to a significant interaction of learning session and recall trial within learning session for the rhyming words, $F(1,13)=13.16$, but not for the nonrhyming words, $F(1,13)=2.43, p=.14$.

The same two undergraduate judges who scored the gist recall rated the extent to which the subjects' recalls demonstrated line structure, independent of how much was recalled. The judgments were based on the spatial layout of the recalls of the orally presented material. Because the subjects heard but did not see the ballads, they could recall a ballad by writing it as one long paragraph, which would not demonstrate any appreciation of the line structure. Alternatively, they could recall it as either a uniform list of separate lines or in complete poetic form, both of which would demonstrate line structure. Each judge provided a proportion for line structure for each recall, reflecting the extent to which the recall demonstrated this constraint as it existed in the original ballads. The judges were reliable with their ratings of line structure correlating .88 over the 56 recall protocols scored. Their judgments were therefore averaged.

A repeated-measures ANOVA compared the line ratings with learning session (first vs. last) and recall trial within learning session (first vs. second) as within factors. There was more line structure in the last learning session than the first, $F(1,13)=22.19$, and more in the second recall trial of each learning session than in the first, $F(1,13)=58.36$. There was also an interaction, $F(1,13)=13.15$, as shown in Figure 2 . For the most part, the subjects 


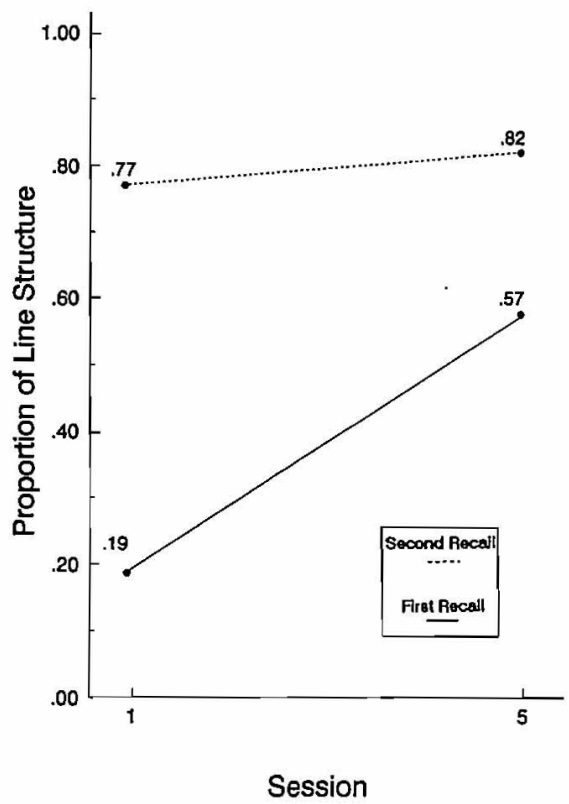

Figure 2. The proportion of line structure demonstrated in the format of the written recalls.

did not demonstrate line structure after hearing their first ballad only once, but did demonstrate line structure after hearing their fifth ballad only once. The .8 proportion for the line measure on the second recall of both learning sessions is a ceiling effect. Two of the 14 subjects never demonstrated line structure in their recalls. If their scores were removed, the .8 proportions would be over .9 for the remaining subjects.

The analyses of the recall data demonstrate that subjects recalled more from the last than the first learning session, and that they became more sensitive with learning to the rhyme and line organization. For the second recall of the first learning session, the proportion of gist recall, the recall of rhyming words, and the recall of line structure are all around .8 to .9 , leaving little room for improvement. Due to these ceiling effects, the effects of exposure to the ballads are greater on the first than the second recall in each learning session for these variables.

Composition of a New Ballad and the Listing of Rules. Thirteen of the 14 subjects could compose a ballad, with 1 subject leaving the page blank. The mean length of the 13 composed ballads was 179 words (range $=66-265$, $S D=59$ ). By comparison, the mean length of the five 10 -stanza ballads learned was 266 words (range $=238-277, S D=25$ ). 
A list of objective regularities was compiled from known characteristics of the popular ballads from which the five learning ballads were drawn (Wallace \& Rubin, 1991) and from the particular five ballads used. In a few bases, these regularities were reworded or divided to allow for more reliable scoring of the composed ballads and explicit rules provided by the subjects. Two undergraduate judges scored the 13 subjects' composed ballads and the rules stated by these 13 subjects for the presence of each regularity. The few cases on which there was disagreement were resolved by a third judge. The regularities are listed in Table 1 with the percentage of the five learning ballads, subject-composed ballads, and rule lists that contained each regularity. The mean number of regularities listed was 18.1 (range $=11-23$, $S D=4.0$ ).

Three observations are worth noting. First, after learning five ballads, subjects could compose ballads that, on the average, implicitly followed $62 \%$ of the objective regularities outlined in Table 1, regularities that cover content, form, word choice, and poetics. Second, the same subjects could, on the average, explicitly state $27 \%$ of these rules. Third, the regularities observed in the composed ballads and the explicitly stated rules are not highly related. The correlation over the last two columns of Table 1 is minimal, $r(28)=.09, p=.64$. As another descriptive statistic to analyze the relation between following as opposed to stating regularities, chi-squared statistics were calculated for each subject individually for whether each of the 30 regularities listed in Table 1 was followed or not versus whether it was stated or not. The 13 chi-squared values ranged from 0.01 to 1.27 with a median of .16. This lack of relation occurred even though the explicitly stated rules were recorded immediately after the composed ballads. A similar lack of relation was found in different domains (Berry \& D. Broadbent, 1984; D. Broadbent, FitzGerald, \& M. Broadbent, 1986; Porter, 1991). If much of explicit attempts to recall information is guided by implicit processes (Nelson, Schreiber, \& McEvoy, 1992), then it is likely that the same implicit processes will also guide the composition of a new ballad and may not be available for explicit comment.

The presence of a regularity in a newly composed ballad does not imply conscious, or even unconscious, use of a stored rule (cf., Mathews et al., 1989; Perruchet \& Pacteau, 1990; Reber, 1989). The usage could be based on stored instances that are cued by common constraint satisfaction problems. Similarly, it is not clear whether the rules consciously stated by the subjects were known before they were requested or were formulated at the time of the request from stored exemplars (Hintzman, 1986).

It is difficult to decide what leads to a particular regularity being observed in the composed ballads. Consider the case of whether a line began with the word "and," which was included in Table 1. In speech (Schiffrin, 1987), in oral traditions (Bakker, 1990), and even in oral presentation of early manuscripts (Gerritsen, 1976), conjunctions are used much as the punctuation 
TABLE 1

Percentage of Use of Specific Regularities

\begin{tabular}{|c|c|c|c|}
\hline Description of the Regularities & $\begin{array}{l}\text { Bollads } \\
\text { Learned }\end{array}$ & Composed & Rule \\
\hline \multicolumn{4}{|l|}{ Content } \\
\hline The main character or characters die & 100 & 69 & 92 \\
\hline A woman (man) betrays a man (woman) & 100 & 85 & 46 \\
\hline Explicit travel of main character(s) & 100 & 85 & 15 \\
\hline $\begin{array}{l}\text { Marriage proposed } \\
\text { Suffering, betrayal, or disobedience }\end{array}$ & 100 & 54 & 15 \\
\hline of loved one(s) besides the lovers & 100 & 15 & 15 \\
\hline Greed or money a motive & 60 & 54 & 8 \\
\hline Description of death, burial, blood, wounds & 100 & 38 & 0 \\
\hline Implied preindustrial setting & 80 & 46 & 30 \\
\hline A moral lesson is obvious & 100 & 30 & 38 \\
\hline The heroine is defenseless against love & 60 & 54 & 8 \\
\hline \multicolumn{4}{|l|}{ Form } \\
\hline No setting & 100 & 100 & 0 \\
\hline First stanza sets up plot of story & 100 & 77 & 30 \\
\hline For most stanzas, each stanza an event & 100 & 38 & 23 \\
\hline Parallel structures, including question/answrer & 60 & 69 & 30 \\
\hline Central action is dramatic and fast paced & 100 & 38 & 8 \\
\hline Action tied to 2 or 3 main characters & 100 & 38 & 8 \\
\hline Dialogue present & 100 & 92 & 54 \\
\hline Dialogue switches without warning & 60 & 54 & 38 \\
\hline First-person singular for some lines & 100 & 92 & 8 \\
\hline Old-fashioned syntax & 100 & 38 & 15 \\
\hline \multicolumn{4}{|l|}{ Word Choice } \\
\hline Most nouns concrete, not abstract & 100 & 77 & 0 \\
\hline Words or phrases repeat & 80 & 77 & 54 \\
\hline Archaic or uncommon words or usage & 100 & 77 & 30 \\
\hline The word "and" begins at least one line & 100 & 77 & 0 \\
\hline Very few words longer than 2 syllables & 100 & 69 & 0 \\
\hline \multicolumn{4}{|l|}{ Poetics } \\
\hline Four lines per stanza & 100 & 85 & 69 \\
\hline Alliteration & 100 & 85 & 0 \\
\hline Lines $1 \& 3$ usually longer than lines $2 \& 4$ & 100 & 46 & 38 \\
\hline Last words of lines $2 \& 4$ usually rhyme & 100 & 69 & 77 \\
\hline Consistent rhythm & 100 & 38 & 62 \\
\hline
\end{tabular}

marks of writing to indicate the start of a new idea. For the traditional ballad singer, the line-initial "and" also can help solve a complex constraint satisfaction problem. The meaning of a line of a ballad can often best be told by starting the line with a stressed syllable, but to follow the iambic pattern of the ballad, a set number of feet has to appear on the line and the first syllable 
of the line has to be unstressed. A common traditional solution to this problem of maintaining the meaning, iambic meter, and proper number of feet in the line is to begin the line with the word "and," which does not change the meaning but adds an initial unstressed syllable. This solution is common, occurring 37 times in the 200 lines of the five learning ballads. That is, almost one fifth of the lines in the five learning ballads began with the word "and," though few of the English sentences that our highly literate subjects read in text or poetry begin this way.

Most of our subjects tried to maintain a consistent rhythm, though they often failed to do so. It is not clear whether the three quarters of the subjects who used a line-initial "and" did so to preserve rhythm or just to imitate without regard to the rhythm the line-initial "and," which occurred so commonly in the ballads they learned. However, after learning only five ballads, the subjects did begin their ballad lines with the word "and," and if they were to continue to learn ballads until they became true experts, they would have a behavior that they would come to use when it was rhythmically correct.

Thus, it is difficult to decide which is the best description of the subjects' behavior. As will be seen in the discussion, the question of the best theory or internal representation is even more of a problem. Examination of the composed ballads themselves, however, do rule out some classes of possible descriptions of composition.

In order to provide a concrete example of the composed ballads, Table 2 displays the ballad that incorporated the most number of rules from Table 1, and Table 3 (p. 450) displays the ballad that had the median number of rules. In Tables 2 and 3, all the words that appeared in any of the five learned ballads are underlined, and any sequences of two or more words that appeared in any of the five learned ballads are enclosed in square brackets. Most of the words used in the two composed ballads appeared in the learning set. This might be expected from any theoretical perspective or proposed mechanism. Many of the words are the common function words of English and most of the others are the common single-syllable words that express the contents listed for the five learned ballads in Table 1. In addition, the general constraint to keep words short and simple is being followed, as is the use of archaic or uncommon language. Thus, descriptions of composition based on constraint satisfaction, or on general rules, or on the copying of parts from one or more ballads, are consistent with the result.

An examination of the sequences of words is more informative. There are no long sequences and the short sequences that do exist are of common combinations of words that, for the most part, are not unique to ballads. There are 32 sequences of words in Tables 2 and 3, of which 29 are two-words long and 3 are three-words long. Eight of the two-word sequences contain the work the, the most common word in printed English, and another function word (and the, by the, but the, for the, of the, and to the). Sixteen of 
TABLE 2

The Composed Ballad that Followed the Most Rules in Table 1

Oh, wife come with me and travel the land and we shall find our fortune

We'll search [for the] treasure that lays beneath

the rocks or 'neath the ruins

Why must we leave our little warm house

and travel about the land

[I have] all that I'll ever want

here within my hands.

I want to provide [for you] [and the] babe

overything you need

But how can a farmer give you enough

just planting down the seed?

So they left [to go] travel the land

[and he] found riches and gold

[Said he], "look upon what we have now.

[You'll never] go hungry or cold"

But he was turned [by the] riches and gold

he ever wanted more

[So he] left his wife and his [little babe]

and went searching for riches again (this line should rhyme with the 2nd one "more")

Each time he searched he found more gold

and bought himself rich lands

He became a lord over [all [of] the] folk

and ruled them with harsh hands.

(story: he finds gold not worth family-but too late to get them back)

(actually_should be more dialogue--either that or names used in lines)

Note: Individual words that appeared in the five learned ballads are underlined; sequences of words that appeared in the five learned ballads are in brackets.

the pairs contain at least one function word or pronoun and are not in any way peculiar to ballads. Four pairs may be more common to ballads than to other discourse (the fair, the blood, innocent blood, and little babe). All 3 three-word sequences could appear anywhere (go along with, he came to, and out of town). If the 2 subjects whose ballads are shown in Tables 2 and 3 were using one ballad, or even large segments of a few ballads, as a base from which alterations were being made, then longer sequences would be expected. Alternatively, if the subjects were beginning to compose by using the longer formulaic sequences of ballads (e.g., (S)He rode and (s)he rode till (s)he came to...), these sequences would be evident. Thus, at least for the two sample ballads selected, the subjects are not composing by cutting and pasting minor modifications of the five learned ballads. 
TABLE 3

The Composed Ballad that Followed the Median number of Rules in Table 1

Lord John rode into the town that day, a wife [he came to] seek

But none were found that pleased Lord John [till he] was there a week

[Her eyes] were blue her hair was golden and her smile was like the sun

Lord John [asked her] [to be] his bride and bear him many sons

[They went] [to the] town of Worcestershire where he found a Parson Brown

in less time than it takes to tell they were married and [out of town]

Lord Mark rode into the town that day, a wife he. [came to] seek

But none were found that pleased Lord Mark [till he] was there a week

The maiden was fair and oh so calm, Lord Mark had found the one

[But the] maiden told him to his dismay, her husband was Lord John

Lord Mark [told her] of gold and jewels, his kingdom and his land

Which all could belong [to [the] tair] maiden [if she] would take his hand

The maiden would not [go olong with] him, for she was very good

Lord Mark then took out his double edged sword and spilled her [innocent blood]

Lord John heard [of the] death of his wife, he heard it from a lark

He then took out his double edged sword to spill [the blood] of Lord Mark

(There would be one more four-line block describing Lord

John's destruction of Lord Mark and his subsequent death over his loss of his wife.)

Note: Individual words that appeared in the five learned ballads are underlined; sequences of words that appeared in the five learned ballads are in brackets.

Cloze Procedure. The percentages of words correctly guessed were tabulated for each of the three ballads. There was an overall advantage for the beginning experts versus the control subjects in the number of blanks filled with exactly the word that appeared in the original version ( $56 \%$ vs. $43 \%$ ), $F(1,24)=22.46$, but this was due mainly to the difference in the one ballad that was learned earlier by the experts $(71 \%$ vs. $44 \%$, for the previously learned ballad); the differences between the beginning experts and the control subjects in the two ballads not seen earlier by the beginning experts were moderate ( $43 \%$ vs. $37 \%$ and $53 \%$ vs. $49 \%$ for the beginning experts vs. the controls, respectively). This leads to a main effect of ballad, $F(2,48)=7.59$, and an interaction of ballad with the expert-novice factor, $F(2,48)=18.85$. If the ballad learned earlier by the experts is excluded from the analysis, there is no longer an effect of expertise, $F(1,24)=2.82, p=.11$.

There is, however, clear evidence that the experts benefited from their experience. Because of the mechanical algorithm of leaving every fifth word blank beginning with the third, there were too few cases of rhyming or alliterating words left blank to analyze. Rhythm, however, exists as a constraint for all blanks. If a response is scored correct as long as it has the same number of syllables as the word that originally appeared in its place, experts do better 


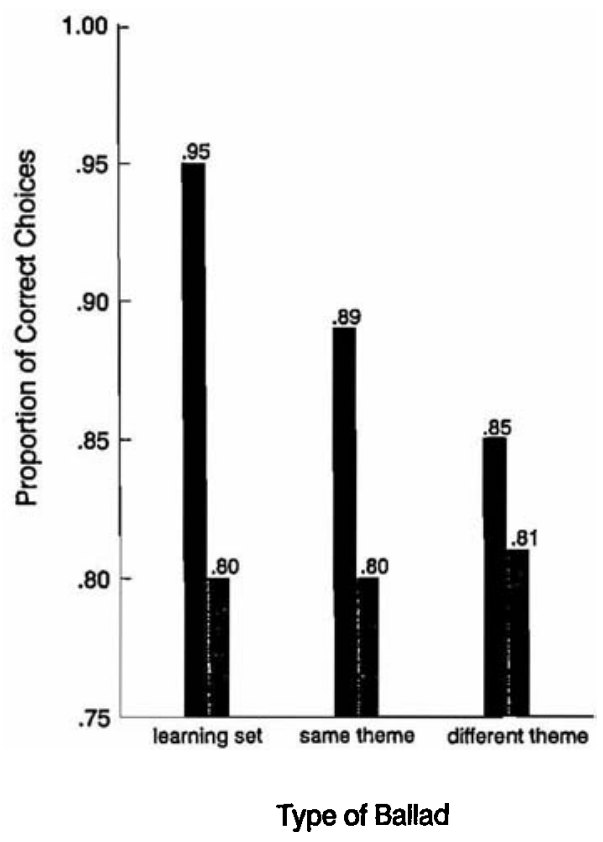

Figure 3. The proportion of original stanzas chosen correctly.

than novices for the ballad seen earlier (93\% vs. $84 \%$ ) as well as for the two ballads that were not seen earlier $(88 \%$ vs. $83 \%$ and $82 \%$ vs. $77 \%)$. For all three ballads there is an effect of expertise, $F(1,24)=13.34$, and of ballad, $F(2,48)=4.70$, but not of the interaction, $F(2,48)=1.17, p=.32$; and the expertise advantage holds if just the two ballads not seen earlier by the experts are included in the analysis, $F(1,24)=5.98$, for expertise, $F(1,24)=7.74$, for ballads, and $F(1,24)=0.04, p=.84$ for the interaction.

Choice Procedure. Overall, the experts did better than the novices in choosing the original stanzas from the changed stanzas, $F(1,112)=18.67$. How well people chose the original stanzas differed among the ballads from the learning set, from similar themes, and from different themes, $F(2,224)=6.52$. Moreover, there was an interaction between the type of ballad and expertise, $F(2,224)=8.90$. As is shown in Figure 3, the novices did essentially the same on all three types of ballads, having had no training on any of them, whereas the experts varied as a function of familiarity with the sets. If each type of ballad is examined separately, there is a significant difference between experts and novices on ballads from the learning set, $F(1,112)=40.90$, and those of similar themes, $F(1,112)=9.37$, but not for ballads of different themes, $F(1,112)=2.80, p=.10$. 
Expertise in the choice task has implications for the way oral traditions are transmitted. If singers are able to select which of two variants is truer to the tradition, in the sense that it preserves more of the constraints of the tradition, then that variant can be transmitted. Through such selection, singers can correct aberrations that appear within the tradition and remove variants that do not preserve constrains.

\section{DISCUSSION}

Undergraduates were able to improve their ability to acquire new information within a genre over the course of learning five ballads. Compared with the first recall of the first ballad, the first recall of the fifth ballad contained about one and a half times as many of the original words. Moreover, the students gained information about the major constraints of the genre. The first recall of the fifth ballad contained about twice as many of the end rhymes as the first recall of the first ballad and contained about three times as much of the rated line structure. In a cloze task, the beginning experts filled in more blanks using the correct number of syllables than novices, and in a task requiring them to pick the better version of a stanza, they succeeded more often than novices. The beginning experts were also able to compose, in $20 \mathrm{~min}$, ballads about two thirds as long as the ballads they learned, and the composed ballads used over half of the 30 constraints found in the set of the five ballads they learned. The beginning experts were also able to state explicitly about one quarter of these constraints, but there was no statistical relationship between the constraints used and the constraints stated. Thus, with a little training, students were able to begin mastering a genre. What are the implications of their accomplishments for our knowledge of cognitive science?

In learning to learn ballads, students made use of whatever organization was apparent to them, not restricting themselves to meaning (Bransford, Franks, Morris, \& Stein, 1979). Expertise in their tasks, in contrast to the tasks given to many other experts, included the use of linguistic surface organization among its structural features and so there was an increase, instead of a decrease, in its use. Appropriate generalization of theories needs to consider the experimental situation (Petrinovich, 1989).

Morris et al. (1977) argued that surface information can be more important than meaning for some tasks, though "learning a list of inputs" ( $p$. 531) usually relies on semantic information. Even in learning a list of inputs, however, subjects become sensitive to the surface organization that is present, if it is as clear as it is in ballads. It is important to stress the role of transferapropriate processing, as Morris et al. did, but the support the material offers for different kinds of processing also needs to be considered (Rubin, 1985). Here, students learned ballads that had both marked surface and deep char- 
acteristics, and they used both in reading that material. But they also gave evidence of using both kinds of characteristics in the cloze, choice, generation, and explicit rule-stating tasks for which they had no specific training. The surface characteristics were appropriate in such a wide range of tasks because they were apparent, regular, structural, and important for the materials in the learning task. Such linguistic surface characteristics are important in a host of other oral traditions (e.g., Kelly \& Rubin, 1988; Lord, 1960) and songs (Hyman \& Rubin, 1990).

Of special interest is that subjects were able to benefit from many characteristics simultaneously. Multiple constraints play an important role in ballads. Each constraint can be an aid in encoding and cuing memories and in sophisticated guesssing. Together, the constraints can greatly limit the alternatives in a nonlinear fashion. Consider the second line from a stanza of Lord Thomas and Fair Annet, one of the ballads used in the first and last learning sessions: "and it was sharp and small." Small is hard to change because it rhymes with the last word of the fourth line of the stanza, wall, and is a near alliteration with sharp as well as the sword and side from the first line of the stanza, "and he had a sword by his side." The word order is hard to change because of the end rhyme and because of the rhythmic pattern of three iambic feet in the second and fourth lines (i.e., weak strong, weak strong, weak strong). Introducing a weapon is necessary to the story told by the ballad, and the form of the description parallels the description of "a little pen-knife" as "and it was keen as a dart" a stanza earlier. Thus, using the constraints together either as cues to recall or in sophisticated guessing greatly increases the chances of producing the word originally heard, or if not, at least a word that would not be easily distinguished by a listener familiar with the genre.

Similar effects can be obtained with more controlled materials taken from the language as a whole (Rubin \& Wallace, 1989). There are many words that are building materials and many words that rhyme with deal, but only one word that is a building material rhyming with deal. Steel has a probability of being guessed of close to zero with the single cues and of one with the joint cues. This is because the dual constraints have two functions. The first, which has been studied extensively in the laboratory, is to cue memory. When each individual constraints cues only one valid response, then existing models of multiple cuing (Jones, 1976; see Morton, 1969, for an earlier alternative) accurately predict the effects of dual cues. When two individual constraints cue more valid responses separately than when combined into a dual cue, as in the steel example just given, no model based on the strengths of individual cues can work (Rubin \& Wallace, 1989). This is because the results also depend on the second function of constraints, their ability to limit choices. This information theory function does not depend on the strengths of the individual constraints, but on the joint distribution of the individual constraints. 
For the example used here, there is only one word that is a building material rhyming with deal, making two very weak cues into a very strong combined dual cue. In constrast to the steel example, there are several words that are animals rhyming with $\log$ (e.g., dog, hog, and frog) or emotions rhyming with add (e.g., mad, sad, glad), for which two moderate cues combine into a moderate combined dual cue. Thus, it is a property of the language that multiple constraints act in a powerful nonlinear fashion. Adding rhythm, alliteration, and more complex narrative structure as well as the other regularities of a genre, amplifies the constraint effects found in the less constrained language of which the ballad genre is a subset.

The findings presented here agree with what we know about real experts. There are no observational studies, but when Wallace (1987, personal communication) questioned expert traditional singers about their learning strategies, they reported a mixture of rote tactics and sensitivity to a variety of constraints. The mention of constraints included, for example, one singer who reported relying on the themes and motifs of ballads that had been acquired from having learned and heard many ballads. Another singer reported using rhyme as a memory aid. In addition, there were reports of reliance on the rhythm, music, and imagery of the ballad for both recall and for learning.

The clear memory task of recalling a ballad is a good place to examine the interplay of the memory metaphor versus the skill metaphor (Bransford, Franks, Nitsch, \& McCarrell, 1977; Gibson, 1966; Kolers \& Roediger, 1984; Rubin, 1988a; Skinner, 1974; Watkins, 1990). Psychologists have viewed human learning from two basic perspectives. The first and most studied, is being called the memory metaphor. In this metaphor, people are presented with material for a single exposure or two and later tested to see what they remember from "the results of a single learning situation." This memory metaphor comes closest to our everyday understanding of the word, memoryas a file or storage of information, or as a place in which units are placed to be retrieved later.

The second perspective can be called the skill metaphor. Here people are presented with varied but related material over many exposures and are tested to see how well they can use the knowledge gained from exposure to this material in a novel situation. The skill metaphor is closer to the metaphor that Lord (1960) postulated for oral traditions and that Bartlett (1932) and Harlow (1949) envisioned for all memory. It has had consistent and eloquent support outside mainstream cognition (e.g., Gibson, 1966; Skinner, 1974). The development of a model of memory as skill, however, has been extremely difficult (Rubin, 1988a), often resulting in either a long list of input-output relations or vague terms like tuning and resonance as a theory, until recent advances in parallel distributed processing. Studies of skilled memory, including this one, are a start at viewing memory as a skill within the general 
framework of cognitive psychology. The process by which people become skilled at memory can be outlined in greater detail, demystifying terms like tuning.

Because the learning of ballads fits well with both metaphors, this article can examine the usefulness of both approaches at the descriptive behavioral level. The distinction between the two classes of models at the theoretical level of internal representation is, however, not possible. A model that stores multiple isolated traces can produce schema-like behavior (Hintzman, 1986). In fact, memory and skill models can usually mimic each other (Barsalou, 1990). The underlying metaphor does not result in predictions of different behavior and, to that extent, the best metaphor cannot be decided by empirical test (Watkins, 1990).

The arguement for the indeterminacy of the internal representations should be examined briefly before showing how different classes of models can show improvements with learning. The simplest working-instance memory model to account for abstraction was proposed by Hintzman (1986). Each time a stimulus is processed, a separate trace consisting of an ordered set of 1,0 , or -1 values is put into memory, one value for each of a predetermined set of features. Memory is probed for recall with a single ordered set of feature values. The model takes the cube of the dot, or inner, product of the probe with each entry in memory as a measure of similarity. To calculate the recalled value, the measure of similarity for each entry in memory is multiplied by each of the entry's feature values and the sum taken for all entries in memory. If the probe used to recall memory has known values for the first three features and zeros for all the rest of the features, the model will return an average value for all the entries in memory, weighted by how similar they were to the probe on the first three values. Thus, the model does no abstraction of any kind until a recall probe is given and then it reports the abstraction without storing it in memory.

Hintzman (1986) showed that this simple model can account in a quantitative fashion for many kinds of data, including prototype abstraction studies designed to provide evidence against instance models. The model also raises the following observation: Any instance model that stores all the data that an abstraction model would use must be powerful enough to mimic the abstraction model; it need only do at recall what the abstraction model would do at encoding.

In contrast to Hintzman's (1986) model, which represents a memory storehouse of isolated instances, consider a generic abstraction model that stores no instances. Rather, each time a new stimulus is encountered, the abstracted representation is changed. Unlike Hintzman's model, there is no way to point to the location or existence of a memory for any particular past stimulus. This model follows the skill metaphor. The model is changed or tuned with additional stimuli, but traces of the stimuli are not stored. One 
would expect such a model to lose information at the benefit of using less long-term memory capacity, but in an article titled "On the indistinguishability of exemplar memory and abstraction in category representation," Barsalou (1990) demonstrated that although parallel distributed processing models do lose information, other forms of abstraction models that also fit the abstraction metaphor do not. Thus, with the exception of parallel distributed processing models, skill, or abstraction, models can be set to lose none of the information initially encoded. Memory, or instance, models can be set to lose information.

The argument being made here, and supported by Hintzman's (1986) simulations and by Barsalou's (1990) proofs, is that from human behavior alone, one cannot distinguish among classes of models, although particular models in the same or different classes can differ. This is because the members of the different classes of models can simulate each other. Thus, there is no way to ask if the beginning experts really operated by storing individual instances, retrieving them for the recall task, and modifying and combining them for the composition, choice, and other tasks. If an instance model is found to account for the data, then a skill, or abstraction, model could be made that assumes the beginning experts formed and operated from an abstracted skill that contained just enough details to perform the tasks. We can, however, briefly examine how generic examples of each of the two proposed classes of models would develop expertise and how this would relate to the existing data and literature.

Consider the state of an instance model after being exposed to only one ballad, assuming for the time that such a large unit can be considered as one entry in memory. When asked for recall and probed with part of the ballad or the context of "the ballad you just heard" there will be little else but the single ballad that will be returned. Extraneous, nonstructural material will be recalled because there will be no summing to return only the recurring features. Included in the extraneous material will be the many aspects of the context of learning that would not be present if the summation were over many different ballad-learning situations. In this way, subjects will be reminded of particular learning situations and of aspects of those situations that an expert might consider irrelevant. With more learning, more entries will be stored in memory and only those features that are common to all entries that are similar to a probe will be returned as a recall.

The model predicts remindings of, and cuings by, extraneous details for subjects just starting to learn a domain. Such remindings of extraneous details are noted in people learning a new task (Ross, 1984), and such cuing by extraneous details are noted in people solving problems of the same kind (Holyoak \& Koh, 1987) as well as in categorization and other tasks (Medin \& Ross, 1989). As entries that are similar with respect to the probed features are added to memory, the summation over all of them will tend to cancel extraneous features, leaving the regularly occurring features. However, if 
the probe contains enough material that is particular to only one entry, even for an expert, that entry can be returned with little contamination from other memories. The recall of past instances that are similar on details that may be extraneous is a common observation in many tasks and one that has advantages as Medin and Ross $(1989$, p. 191) noted: "Specificity may make access to an application of relevant knowledge easier, may permit graceful updating of knowledge, may protect the cognitive system from incorrect or inappropriate inferences, and may provide just the sort of context sensitivity that much of our knowledge should, in fact, have." Such remindings and cuings are not failings of expertise.

At the level of detail given, the same story could be told in nearly the same way for a skill, or abstraction, model that stored no instances. Initially, the abstraction would be set by only one instance, and only that instance would be recalled if enough context or other information were in the probe. As more instances were added, the abstraction would depend less on each instance and extraneous information would be lost unless there were enough cues in the probe to reinstate the activity present for one probe. Of course, for either model, a loss of information with time could be allowed in which case more recent instances would be better represented in memory and therefore could provide a better match to the probe and be easier to retrieve.

A major problem in applying a specific model from either class of models in a predictive fashion to the data collected in this article is that the subjects come to the study with prior knowledge of the language, its poetics, common themes, and all forms of general world knowledge. Thus, their storehouses of memories or sets of weights are set, for the most part, prior to the study. Examination of the rapidity with which the subjects learn to use the poetic and rhythmic devices in their recalls, and compose ballads that follow the rules listed in Table 1, suggests that there was considerable sensitivity to these devices before the experiment began. This is reinforced by the lack of long sequences of words copied from the five learned ballads in the two composed ballads analyzed in detail; such composition indicates considerable knowledge accumulated prior to the five learned ballads. This is not to minimize the achievements of the beginning experts. There are many different domains with many different kinds of constraints that could have been given to the subjects, and it is likely that they could have done well with any of them. Without detecting and using the small subset of actual constraints in the subgenre presented to them, their progress would not have been possible.

\section{REFERENCES}

Ackerman, P.L. (1987). Individual differences in skill learning: An integration of psychometric and information processing perspectives. Psychological Bulletin, 102, 3-27.

Bakker, E.J. (1990). Homeric discourse and enjambement: A cognitive approach. Transactions of the American Philological Association, 120, 1-21. 
Barsalou, L.W. (1990). On the indistinguishability of exemplar memory and abstraction in category representation. In T.K. Srull \& R.S. Wyer, Jr. (Eds.), Advances in social cogniton: Vol. 3. Content and process specificity in the effects of prior experiences. Hillsdale, NJ: Erlbaum.

Bartlett, F.C. (1932). Remembering: A study in experimental and social psychology. London: Cambridge University Press.

Berry, D.C., \& Broadbent, D.E. (1984). On the relationship between task performance and associated verbalizable knowledge. The Quarterly Journal of Experimental Psychology, $36 A, 209-231$.

Bransford, J.D., Franks, J.J., Morris, C.D., \& Stein, B.S. (1979) Some general constraints on learning and memory research. In L.S. Cermak \& F.I.M. Craik (Eds.), Levels of processing in human memory. Hillsdale, NJ: Erlbaum.

Bransford, J.D., Franks, J.J., Nitsch, K.E., \& McCarrell, N.S. (1977). Toward unexplaining memory. In R. Shaw \& J. Bransford (Eds.), Perceiving, acting, and knowing: Toward an ecological psychology. Hillsdale, NJ: Erlbaum.

Broadbent, D.E., FitzGerald, P., \& Broadbent, M.H.P. (1986). Implicit and explicit knowledge in control of complex systems. British Journal of Psychology, 77, 33-50.

Chase, W.G., \& Ericsson, K.A. (1981). Skilled memory. In J.R. Anderson (Ed.), Cognitive skills and their acquisition. Hillsdale, NJ: Erlbaum.

Chase, W.G., \& Simon, H.A. (1973). Perception in chess. Cognitive Psychology, 4, 55-81.

Chi, M.T.H., Feltovich, P.J., \& Glaser, R. (1981). Categorization and representation of physics problems by experts and novices. Cognitive Science, 5, 121-152.

Child, F.J. (1882-1898). The English and Scottish popular ballads (Parts 1-10). Boston: Houghton Mifflin.

Dee-Lucas, D., \& Larkin, J.H. (1988). Novice rules for assessing importance in scientific texts. Journal of Memory and Language, 27, 288-308.

Engle, R.W., \& Bukstel, L. (1978). Memory processes among bridge players of differing expertise. American Journal of Psychology, 91, 673-689.

Ericsson, K.A. (1985). Memory skill. Canadian Journal of Psychology, 39, 188-231.

Ericsson, K.A., \& Harris, M.S. (1990). Expert chess memory without chess knowledge: $A$ training study. Paper presented at the 31st Annual Meeting of the Psychonomic Society, New Orleans.

Gerritsen, W.P. (1976). Corrections and indications for oral delivery in the Middle Dutch Lancelot manuscript. Neerlandica Manuscripta: Essays presented to G.I. Lieftinck (Vol. 3). Amsterdam: A.L. van Gendt \& Co.

Gibson, J.J. (1966). The senses considered as perceptual systems. Boston: Houghton Mifflin.

Glaser, R., \& Chi, M.T.H. (1988), Overview. In M.T.H. Chi, R. Glaser, M.J. Farr (Eds.), The nature of expertise. Hillsdale, NJ: Erlbaum.

Harlow, H.F. (1949). The formation of learning sets. Psychological Review, 56, 51-65.

Hintzman, D.L. (1986). "Schema abstraction" in a multiple-trace memory model. Psychological Review, 93, 411-428.

Holding, D.H. (1985). The psychology of chess skill. Hillsdale, NJ: Erlbaum.

Holyoak, K.J., \& Koh, K. (1987). Surface and structural similarity in analogical transfer. Memory \& Cognition, 15, 332-340.

Hunter, I.M.L. (1990). Exceptional memory performers: The motivational background. In M.J.A. Howe (Ed.), Encouraging the development of exceptional skills and talents. Leicester, UK: The British Psychological Society.

Hyman, I.E., Jr., \& Rubin, D.C. (1990). Memorabeatlia: A naturalistic study of long-term memory. Memory and Cognition, 18, 205-214.

Intons-Peterson, M.J., \& Smyth, M.M. (1987). The anatomy of repertory memory. Journal of Experimental Psychology: Learning, Memory, and Cognition, 13, 490-500.

James, W. (1890). The principles of psychology. New York: Henry Holt \& Co. 
Jones, G.V. (1976). A fragmentation hypothesis of memory: Cued recall of pictures and of sequential position. Journal of Experimental Psychology: General, 105, 227-293.

Kelly, M.H., \& Rubin, D.C. (1988). Natural rhythmic patterns in English verse: Evidence from child counting-out rhymes. Journal of Memory and Language, 27, 718-740.

Kolers, P.A., \& Roediger, H.L., III. (1984). Procedures of mind. Journal of Verbal Learning and Verbal Behavior, 23, 425-449.

Lord, A.B. (1960). The singer of tales. Cambridge, MA: Harvard University Press.

Luria, A.R. (1968). The mind of a mnemonist. New York: Basic Books.

Mathews, R.C., Buss, R.R., Stanley, W.B., Blanchard-Fields, F., Cho, J.R., \& Druhan, B. (1989). Role of implicit and explicit processes in learning from examples: A synergistic effect. Journal of Experimental Psychology: Learning, Memory, and Cognition, 15, 1083-1100.

Medin, D.L., \& Ross, B.H. (1989). The specific character of abstract thought: Categorization, problem solving, and induction. In R.J. Sternberg (Ed.), Advances in the psychology of human intelligence (Vol. 5). Hillsdale, NJ: Erlbaum.

Morris, C.D., Bransford, J.D., \& Franks, J.J. (1977). Levels of processing versus transfer appropriate processing. Journal of Verbal Learning and Verbal Behavior, 16, 519-533.

Morton, J. (1969). Interaction of information in word recognition. Psychological Review, 76, $165-178$.

Neisser, U. (1982). Memory observed. San Francisco: W.H. Freeman.

Nelson, D.L., Schreiber, T.A., \& McEvoy, C.L. (1992). Processing implicit and explicit representations. Psychological Review, 99, 322-348.

Noice, H. (1991). The role of explanations and plan recognition in the learning of theatrical scripts. Cognitive Psychology, 15, 425-460.

Noice, H. (1992). Elaborative memory strategies of professional actors. Applied Cognitive Psychology, 6, 417-427.

Novick, L.R. (1988). Analogical transfer, problem similarity, expertise. Journal of Experimental Psychology: Learning, Memory, and Cognition, 4, 510-520.

Perruchet, P., \& Pacteau, C. (1990). Synthetic grammar learning: Implicit rule abstraction or explicit fragmentary knowledge. Journal of Experimental Psychology General, 1/9, 264-275.

Petrinovich, L. (1989). Representative design and the quality of generalization. in L.W. Poon, D.C. Rubin, \& B.A. Wilson (Eds.), Everyday cognition in adult and later life. Cambridge, England: Cambridge University Press.

Porter, D.B. (1991). Computer games and cognitive processes: Two tasks, two modes, too much. British Journal of Psychology, 82, 343-357.

Reber, A.S. (1989). Implicit learning and tacit knowledge. Journal of Experimental Psychology: General, 118, 219-235.

Ross, B.H. (1984). Remindings and their effects in learning a cognitive skill. Cognitive Psychology, 16, 371-416.

Rubin, D.C. (1985). Memorability as a measure of processing: A unit analysis of prose and list learning. Journal of Experimental Psychology: General, 114, 213-238.

Rubin, D.C. (1988a). Go for the skill. In U. Neisser \& E. Winograd (Eds.), Remembering reconsidered: Ecological and traditional approaches to the study of memory. Cambridge, England: Cambridge University Press.

Rubin, D.C. (1988b). Learning poetic language. In F. Kessel (Ed.), The development of language and language researchers: Essays in honor of Roger Brown. Hillsdale, NJ: Erlbaum.

Rubin, D.C., \& Kontis, T.C. (1983). A schema for common cents. Memory \& Cognition, 11, 335-341.

Rubin, D.C., Stolzfus, E.R., \& Wall, K.L. (1991). The abstraction of form in semantic categories. Memory and Cognition, 19, 1-7. 
Rubin, D.C., \& Wallace, W.T. (1989). Rhyme and reason: Analyses of dual cues. Journal of Experimental Psychology: Learning, Memory, and Cognition, 15, 698-709.

Schiffrin, D. (1987). Discourse markers. Cambridge, England: Cambridge University Press.

Schoenfeld, A.H., \& Herrmann, D.J. (1982). Problem perception and knowledge structure in expert and novice mathematical problem solvers. Journal of Experimental Psychology: Learning, Memory, and Cognition, 8, 484-494.

Singley, M.K., \& Anderson, J.R. (1989). The transfer of cognitive skill. Cambridge, MA: Harvard.

Skinner, B.F. (1974). About behaviorism. New York: Alfred A. Knopf.

Smith, M.U. (1990). Knowledge structures and the nature of expertise in classical genetics. Cognitive and Instruction, 7, 287-302.

Staszewski, J.J. (1989). Exceptional memory: The influence of practice and knowledge on the development of elaborative encoding strategies. In W. Schneider \& F.E. Weinert (Eds.), Interactions among aptitudes, strategies, and knowledge in cognitive performance. New York: Springer-Verlag.

Thompson, C.P., Cowan, T., Frieman, Jerome, Mahadevan, R.S., Vogl, R.J., \& Frieman, Jeanne (1991). Rajan: A study of a memorist. Journal of Memory and Language, 30, 702-724.

Thorndyke, P.W. (1977). Cognitjve structures in comprehension and memory of narrative discourse. Cognitive Psychology, 9, 77-110.

Wallace, W.T. (1991). The creation of a new ballad: Evidence of characteristic knowledge. Unpublished manuscript, Fuqua School of Business, Duke University, Durham, NC.

Wallace, W.T. (1992). Memory for music: The effect of melody on recall of text. Unpublished manuscript, Fuqua School of Business, Duke University, Durham, NC.

Wallace, W.T., \& Rubin, D.C. (1988a). Memory of a ballad singer. In M.M. Gruenberg, P.E. Morris, \& R.N. Sykes (Eds.), Practical aspects of memory: Current research and issues: Vol 1. Memory in everyday life. New York: Wiley.

Wallace, W.T., \& Rubin, D.C. (1988b). "The wreck of the old 97": A real event remembered in song. In U. Neisser \& E. Winograd (Eds.), Remembering reconsidered: Ecological and traditional approaches to the study of memory. Cambridge, England: Cambridge University Press.

Wallace, W.T., \& Rubin, D.C. (1991) Characteristics and constraints in ballads and their effect on memory. Discourse Processes, 14, 181-202.

Watkins, M.J. (1990). Mediationism and the obfuscation of memory. American Psychologist, 45, 328-335.

White, N.1. (1952). The Frank C. Brown collection of North Carolina folklore (Vol. 2). Folk ballads from North Carolina. Durham, NC: Duke University Press.

White, N.I. (1957). The Frank C. Brown collection of North Carolina folklore (Vol. 4). The music of the ballads. Durham, NC: Duke University Press.

\section{APPENDIX}

\section{The 10-Verse Versions of the First and Last Presented Ballads}

\section{Lord Thomas and Fair Eleanor}

(Lord Thomas \& Fair Annet; Brown 19M, Child 73)

'O mother, $O$ mother, come riddle to me,

And riddle us both as one,

And say shall I marry the fair Eleanor

Or bring the brown girl home?' 
'The brown girl she hath house and lands, Fair Eleanor she hath none.

So I would advise you with all of my mind To bring the brown girl home.'

He rode and he rode till he came to the castle;

He made the knocker to ring.

There was none so ready as the fair Eleanor

To rise and let him in.

'Bad news, bad news, Lord Thomas,' she cried, 'Bad news do you bring to me.

I thought to have been myself your bride And you bridegroom to me.'

'O mother, O mother, come riddle to me, And riddle us both as one,

And say shall I go to Lord Thomas's wedding

Or tarry alone at home?'

'There are many that are our friends, daughter, But thousands are our foes.

So I would advise you with all of my mind

To Lord Thomas's wedding don't go.'

She rode and she rode till she came to the hall;

She made the knocker to ring.

There was none so ready as Lord Thomas himself

To rise and let her in.

The brown girl she had a little pen-knife, And it was keen as a dart;

And between the short ribs and the long

She pierced fair Eleanor's heart.

Lord Thomas he had a sword by his side, And it was sharp and small;

And with it he cut off the brown girl's head

And he flung it against the wall.

'Oh, dig my grave, oh, dig my grave,

Oh dig it wide and deep.

Bury fair Eleanor in my arms,

The brown girl at my feet.'

\section{The House Carpenter \\ (James Harris or The Daemon Lover; \\ Brown 40A, Child 243)}

'We'll meet, we'll meet, my own true love,'

'We'll meet, we'll meet,' he replied;

'Im just returnin' from the salt, salt sea

And it's all for the love of thee.' 
'If you will leave your house carpenter

And go along with me,

I'll take you where the grass grows green

On the banks of Sweet Willie.'

'If I will leave my house carpenter

And go along with thee,

Have you anything to maintain me upon

And keep me from slavery?'

'I have five ships on the ocean wide

A-sailin' for dry land,

A hundred and fifty bold seamen

For to be at your command.'

She picked up her sweet little babe

And kisses she gave it three,

Saying, 'Stay at home, my sweet little babe,

And keep your pappy company.'

She had not been on sea two months,

I'm sure it was not three,

Until she lamented in her true love's ship

And wept most bitterly.

'Are you a-weepin' for my silver or my gold,

Or either for my store?

Or are you a-weepin' for your house carpenter

That you'll never see no more?'

'I'm not a-weepin' for your silver or your gold

Or either for your store;

I'm just a-weepin' for my sweet little babe

That I never shall see no more.'

She had not been on the sea three months,

I'm sure it was not four,

Until there sprung a leak in her true love's ship

And sunk it to rise no more.

'A curse, a curse on all seamen,

A curse for evermore;

For you have robbed me of my house carpenter

That I never shall see any more.'

Ballads adapted from White, N.I. (Ed.). (1952). The Frank C. Brown Collection of North Carolina Folklore: Vol 2. Folk ballads from North Carolina

(pp. 77-79, 171-173). Copyright Duke University Press, Durham, NC.

Reprinted with permission of the publisher. 